This is the pre-print version of:

Shin, W., \& Li, B. (2017). Parental mediation of children's digital technology use in Singapore. Journal of Children and Media, 11(1), 1-19.

\title{
PARENTAL MEDIATION OF CHILDREN'S DIGITAL TECHNOLOGY USE IN SINGAPORE
}

\author{
Wonsun Shin* \& Benjamin Li
}

Running head: Parental Mediation of Children's Digital Technology Use Word count of the manuscript: 9,379 words (excluding the title page and abstract)

Manuscript accepted for publication in the Journal of Children and Media.

* All correspondence concerning this manuscript should be addressed to Wonsun Shin (wonsun.shin@unimelb.edu.au). 


\title{
PARENTAL MEDIATION OF CHILDREN'S DIGITAL TECHNOLOGY USE IN SINGAPORE
}

\begin{abstract}
This study examines parental mediation of children's digital technology use and factors associated with it. A survey of 557 parents of primary school children in Singapore revealed that parents tend to utilize simpler mediation strategies to supervise and control their children's digital technology use. Findings also suggest that parental mediation is more a function of parents' usage of digital technology and parent-child interaction patterns rather than parent-child demographic characteristics.
\end{abstract}

Keywords: Parental mediation, digital technology use, Singapore, children 
Parental Mediation of Children's Digital Technology Use 2

\section{PARENTAL MEDIATION OF CHILDREN'S DIGITAL TECHNOLOGY USE IN SINGAPORE}

\section{Introduction}

The increasing accessibility of consumer digital devices has seen a rise in digital media use among children (Ofcom, 2014; Rideout, 2013, theAsianparent Insights, 2014). The prevalence of digital technology has not only changed the way children learn and absorb knowledge, but also transformed the way they communicate and interact with each other (Wartella, Rideout, Lauricella, \& Connell, 2013). While it is debatable whether these new technologies have an overall positive or negative impact on children, scholars suggest that the impact of media on children largely depends on the proper management and mediation of its use (Clark, 2011).

However, the changing media environment poses challenges for parents. Today's children, known as "digital natives," are tech-savvy and confident about their digital skills, and their knowledge and understanding of digital technology often exceeds that of their parents (Ofcom, 2014; Rideout, 2013; Tufte \& Rasmussen, 2010). In addition, many digital devices are portable and mobile, making it harder for parents to closely monitor children's use of them. Given these circumstances, it is important to investigate how parents cope with these new challenges. Thus, this study has the following objectives: (1) to understand the prevalent methods that parents in Singapore adopt to mediate children's digital technology use and (2) to investigate factors associated with different types of parental mediation applied to children's digital technology use. 
There are two research gaps in the parental mediation literature, especially related to children's digital technology use. First, the majority of studies examine children's participation in a single media activity, such as using the internet (e.g., Lee \& Chae, 2007), playing video games (e.g., Nikken \& Jansz, 2006), or using social media (e.g., Shin \& Ismail, 2014). However, children today are multitaskers, often using multiple digital devices at the same time (Gentile, Reimer, Nathanson, Walsh, \& Eisenmann, 2014; Gutnick, Robb, Takeuchi, \& Kotler, 2010; Tufte \& Rasmussen, 2010). They can surf the web using their computers while texting their friends on their smartphones and playing games on their tablets. It appears that it is not sufficient to examine parental mediation on just one single form of media alone. The challenge for parents in the digital age is to adopt mediation strategies that take into account the media multitasking tendencies of their children. Hence, there is a need to explore parental mediation with regard to children's digital screen time across a series of digital devices. Second, the majority of studies in this field have either been conducted in the US or in Europe. There is reason to believe that cultural and value orientations may determine parental styles and mediation strategies (Kirwil, 2009). Hence, it is important to explore parental mediation and its antecedents in non-Western societies.

This study uses the phrase "digital technology" to refer to digital devices that allow individuals to consume and interact with media. While scholars typically include computers and smartphones in studies of digital technology (Pearce \& Rice, 2013), tablet ownership has been on the rise in recent years with the United States and Singapore seeing 51\% and 47\% penetration rates respectively (Nielsen, 2014, 2015). The popularity and pervasiveness of tablets prompted us to include these portable devices as well. Thus, we consider children's use of computers, smartphones, and tablets in this study of digital technology. We examine parental mediation of 
children's overall digital technology use (total screen time) rather than parental mediation of each type of digital media, for the aforementioned reasons - modern children are multitaskers who use multiple types of digital media simultaneously (Gentile et al., 2014; Gutnick et al., 2010; Tufte \& Rasmussen, 2010). We focus on primary school children in Singapore since digital technology is pervasive and primary school students in the country are encouraged to use it both at home and in school, but not much is known about how parents of primary school children in Singapore engage in digital technology mediation.

\section{Research Context: Singapore's Digital Technology Landscape}

Singapore is a technologically capable and well-connected nation. The internet penetration rate in Singapore is $81 \%$, almost double the global average (We Are Social, 2015). Government support for a national high speed internet has propelled the city-state to fourth in the world with regard to the average broadband speed per user (World Economic Forum, 2015). The mobile phone penetration rate is $148 \%$, suggesting that Singaporeans own more than one mobile phone on average (Infocomm Development Authority of Singapore, 2015). Eighty-five percent of Singaporeans use a smartphone, and $40 \%$ use a tablet (Consumer Barometer, 2014). It is no wonder that Singapore has been ranked second in the world in technology usage for five consecutive years (World Economic Forum, 2014).

These impressive figures suggest that Singaporeans are tech-savvy and use digital technology with ease. However, it also means that individuals, especially young people, are more likely to be exposed to the dangers and risks of the online and mobile environment, such as privacy invasion or accidental exposure to age-inappropriate content (Trend Micro, 2014). Because parents are the primary caregivers and socialization agents for children, educational programs and campaigns in Singapore have emphasized parental role in preventing exposure to 
these dangers. In 2008, for example, Singapore's Ministry of Education launched an Information-Communication Technology master plan. The plan includes a framework to guide schools in planning and developing cyber wellness programs, which provide parents with handbooks containing tips to detect and manage cyber-related issues their children may have (Ministry of Education, 2013a). In 2013, the ministry launched the "iZ HERO" exhibition at the Singapore Science Center to provide children with an exciting approach to learning about responsible digital citizenry. Visitors engaged in interactive storytelling where they fought against animated armies that represented various "digital dangers". Parents were also provided with tips to manage children's digital technology use (Ministry of Education, 2013b). Recently, the ministry developed a mobile app called "C-Quest" to encourage conversations on cyber wellness between parents and their children aged 10-14 (Ministry of Education, 2014).

Despite the push for greater public education and awareness, little is known about how parents in Singapore monitor, control, and inform children's digital technology use, and whether there are any factors that account for the different strategies parents use to manage children's digital technology use. Most studies reviewed in this paper were conducted in the West, and Singapore presents herself as a unique landscape. As mentioned previously, Singapore ranks highly in terms of proliferation of technology and digital savviness. This is in contrast to countries such as the United States where mobile phone penetration rates are unlike those in Singapore and where the technological readiness rankings are not as remarkable. The advanced technological environment and digital climate in Singapore may lead parents to engage in parental mediation strategies differently from parents in Western countries. Understanding how parents in technologically advanced countries such as Singapore cope with the increasing influence of the digital environment on their children may be useful for parents in Western 
countries in the future, as these countries become more technologically connected and children in these places mature in their tech savviness.

Moreover, the value orientation of a country may influence the type of mediation strategies parents undertake. Kirwil (2009) found the tendency of European parents to engage in restrictive or non-restrictive mediation strategies were dependent on the value orientations of the 18 European countries the study surveyed. Singapore, which has embraced modernism while holding on firmly its roots in Asian values (Chang, Wong, \& Koh, 2003), presents a unique landscape for this study. As such, this study uses the parental mediation literature as a guiding theoretical framework with Singapore as a particular backdrop. The subsequent sections review the literature of parental mediation, identify gaps in the literature, and pose two research questions.

\section{The Role of Parents in Children's Media Use}

Parents influence children's behavior from the moment they are born (Buijzen \& Valkenburg, 2005). Parent and child are "part of a biologically intertwined system that strongly supports the [child's] socialization process" (Bugental \& Grusec, 2006, p. 368), and parents are often motivated by this strong relationship to handle and mediate the child's behavior in the face of social demands and new situations. Parents, being "the most influential people in the development and socialization of children” (Sonck, Nikken, \& de Haan, 2013, p. 96), also take primary responsibility for guiding their children's media behavior. Proper mediation of children's media use by parents is known to result in positive outcomes such as decreased exposure to privacy risks, decreased exposure to child-inappropriate media content, and heightened understanding of media content (Buijzen \& Valkenburg, 2005; Lee \& Chae, 2007; Lwin, Stanaland, \& Miyazaki, 2008). 
Three general approaches to the mediation of children's media use have been identified. Active mediation refers to parents explaining and discussing media with their child. Restrictive mediation happens when parents set rules regarding the amount of time and the kind of content with which their child is allowed to engage. Lastly, co-use refers to shared usage of media between parents and children without parental instruction or discussion (Austin, Bolls, Fujioka, \& Engelbertson, 1999; Clark, 2011). Research suggests that different forms of the parental mediation result in different outcomes. One of the consistent findings in regard to the outcomes of different forms of parental mediation is that active mediation is more effective than the other two forms of mediation (e.g., Buijzen \& Valkenburg, 2005; Lwin et al., 2008; Warren, 2001), primarily because active mediation based on parent-child conversation and discussion is more likely to cultivate critical thinking skills in children (Fujioka \& Austin, 2003) and to lead children to be more responsive to parents' initiatives (Grusec \& Davidov, 2007). Research also suggests that too much restriction can cause unintended consequences such as a boomerang effect (Lwin et al., 2008) or a forbidden fruit syndrome (Nathanson, 2002), especially when it is imposed on older children who pursue more autonomy from parents (Lwin et al., 2008). The effects of co-use has not been compellingly verified as prior studies have demonstrated that couse can also be viewed by children as parental endorsement to the media content rather than deliberate monitoring efforts, especially in television viewing contexts (Austin et al., 1999; Nathanson, 2002).

While the above three strategies have been identified in research on television viewing (Clark, 2011), a number of studies examining parental mediation of children's use of the internet and video games have applied the three forms of parental mediation (e.g., Eastin, Greenberg, \& Hofschire, 2006; Lwin et al., 2008; Nikken \& Jansz, 2006; Shin \& Huh, 2011; Shin, Huh, \& 
Faber, 2012). However, the advent of the digital age has resulted in a generation of children that are experts at multitasking with digital technology (Gentile et al., 2014; Gutnick et al., 2010; Tufte \& Rasmussen, 2010), and the complexity of new digital technology, characterized by its focus on multiple activities, multi-media, active content production, and social interactions, have posed new challenges to parents guiding their children through all of these activities (Sonck et al., 2013). Addressing the changes in the media environment, some studies have identified additional types of parental mediation strategies. For instance, Livingstone and Helsper (2008) identified a strategy known as monitoring, which refers to parents' checking of children's email messages or the sites that children have visited. This can be conducted overtly or covertly after the child's internet use. A similar concept called supervision was identified by Nikken and Jansz (2014), which refers to parents' keeping an eye on the child and the device and allowing children to surf the web only when parents are present. While monitoring involves examining the sites and messages that a child is involved with and can happen with or without the child being around, supervision happens when the parent is physically together with the child.

What is less known is the extent to which parents practice each mediation strategy. Livingstone and Helsper (2008) surveyed teenagers aged 12-18 and their parents in the UK and found that parents often adopt strategies used in television mediation to deal with the new challenges posed by the internet. Nikken and Jansz (2014) surveyed parents of children aged 212 in the Netherlands and found that supervision was the most common parental mediation strategy parents used to mediate children's internet use. Sonck et al. (2013) found that active safety mediation was the most common strategy employed by Dutch parents of children aged 916 using the internet. Khurana, Bleakley, Jordan, and Romer (2015) surveyed parents of 
American adolescents and found that parental monitoring was practiced twice as often as restrictive strategies.

Overall, there seems to be a lack of consensus as to which mediation strategy is most popular among parents with regard to children's use of digital technology. In addition, each of the prior studies focused on a different age group. Thus, it is unclear whether particular parental mediation strategies are more or less prevalent among parents of a certain age group, such as primary school aged children. Finally, most existing studies have focused on children's internet use, mostly in Western societies with an individualistic orientation. It is unclear how parents in Singapore, a non-Western society with largely collectivistic values (Smith, Dugan, \& Trompenaars, 1996), manage children's overall digital technology use and screen time. Hence, the following research question is proposed:

RQ1. To what extent are different mediation strategies used by parents in Singapore to influence their children's use of digital technology?

\section{Factors Influencing Parental Mediation Styles}

While research suggests that parents in general try to control and supervise their children's media use, not all parents practice the same levels and types of parental mediation. To enhance our understanding of parental mediation, it is important to explore what factors influence parental mediation practices. This study examines three groups of antecedents of parental mediation: parent-child individual characteristics, parents' usage and perception of media, and parent-child interactions. Concurrently analyzing these three groups of factors will allow us to examine how personal (individual characteristics and media use and perception) and relational (family interaction) factors can influence parental mediation altogether and provide more comprehensive insights into parental mediation of children's digital technology use. 


\section{Parent-Child Individual Characteristics}

A number of studies have examined individual characteristics of children and parents as factors affecting parental mediation. For instance, children's age has been found to be negatively associated with the level of parental mediation of television (e.g., Nathanson, 2001; Valkenburg, Krcmar, Peeters, \& Marseille, 1999), internet (e.g., Eastin et al., 2006; Livingstone \& Helsper, 2008) and video game use (Nikken \& Jansz, 2006; Shin \& Huh, 2011), suggesting that parents tend to exhibit a higher level of mediation with younger children.

However, a deeper look into the literature reveals that age becomes a less important or even a non-significant predictor of parental mediation when parents' perceptions of media are included as predictors of parental mediation in multivariate analyses (e.g., Valkenburg et al., 1999; Warren, Gerke, \& Kelly, 2002). Valkenburg et al. (1999) and Sonck et al. (2013) argued that it could be parents' perceptions of or concerns about media, rather than children's age, that motivate parents to impose higher levels of parental mediation on their children.

The arguments made by Valkenburg et al. (1999) and Sonck et al. (2013) can further explain some of the mixed findings regarding the relationship between parental mediation and other demographic variables such as children's and parents' genders. Some studies have found that boys tend to receive more parental mediation than girls (e.g., Eastin et al., 2006; Hoffner \& Buchanan, 2002) while others have found the opposite (e.g., Livingstone \& Helsper, 2008; Nikken \& Jansz, 2006) or no significant gender differences (Nathanson, 2001; Nikken, Jansz, \& Schouwstra, 2007). Valkenburg et al. (1999) demonstrated that parents were more concerned about girls' television viewing than boys' and that the concerns led to greater mediation of girls' viewing. That is, parental mediation is more a function of the parent's media-related perceptions rather than the child's gender itself. Regarding the gender of parents, while some studies have 
demonstrated that mothers are more likely than fathers to practice parental mediation (e.g., Nikken \& Jansz, 2006; Valkenburg et al., 1999), others found no association between the gender of parents and parental mediation (e.g., Hoffner \& Buchanan, 2002; Warren, 2001). Showing that the relationship between parent gender and parental mediation became weaker when parental involvement variables (e.g., parent and child shared activities) were entered into regression analyses, Warren et al. (2002) demonstrated that the degree to which parents were involved in childrearing played a more important role in parental mediation than parents' gender.

Overall, studies suggest that demographic variables alone cannot sufficiently explain how parents mediate children's media use, in both traditional and digital media contexts. Other parental factors such as parents' media perception and usage as well as parent-child relationship and interaction patterns should also be considered as potential factors influencing parental mediation practices.

\section{Parent's Perception and Usage of Media}

As discussed earlier, a number of studies have demonstrated that the way parents engage in parental mediation is influenced by how they feel about media. Nathanson (2001) found that the degree to which parents perceived violent television programs to be important and useful for themselves was negatively associated with their engagement in restrictive mediation. Warren (2001) found that parents who were highly concerned about child-inappropriate television content were more likely to implement higher levels of active and restrictive mediation. Outside the television context, Nikken and Jansz (2006) and Shin and Huh (2011) found that parents' negative perceptions of video games were positively associated with both active and restrictive parental mediation. Similar findings have been reported in studies on parental mediation of children's internet use (Lee, 2013; Nikken \& Jansz, 2014). 
Research also suggests that parents' own use of media affect the way they engage in parental mediation. Livingstone and Helsper (2008) found that parents who claimed to have stronger skills in using the internet engaged in more mediation of their children's internet use. Sonck et al. (2013) also found that parents who were confident about their internet skills monitored their children's internet use more often. However, it is unclear how the amount of time parents spend on different types of media affects mediation practices. While some researchers found a positive association between the amount of time parents spent on media and the level of parental mediation (e.g., Livingstone \& Helsper, 2008), other studies (e.g., Nikken \& Jansz, 2014; Sonck et al., 2013) found no association between the two variables.

Overall, there seems to be a close association between parents' perception of media and parental mediation. However, little is known about how parents' usage of media is associated with different types of parental mediation of children's digital technology use. This study examines both the amount of time parents spend on digital technology and the range of digital activities that parents engage as potential antecedents of parental mediation of children's digital technology use.

\section{Parent-Child Interaction}

Parental mediation involves interpersonal communication and interaction between a parent and child (Clark, 2011). Therefore, parent-child interaction factors are presumed to play an important role in explaining parental mediation practices. However, very little is known about how parent-child interaction factors are associated with different types of parental mediation of children's digital technology use. This study examines parenting style and parent involvement as parent-child interaction factors. 
Research suggests that parenting style, which refers to parents' pervasive socialization tendencies displayed across a wide range of parent-child interactions (Baumrind, 1971), can have substantial effects on parents' childrearing practices (Grusec \& Davidov, 2007). Scholars have identified and examined two broad dimensions of parenting style —demandingness and responsiveness (Baumrind, 1971; Darling and Steinberg, 1993; Steinberg, Lamborn, Dornbusch, \& Darling, 1992). Demandingness refers to a parent's willingness to act as a socialization agent through supervision and maturity demands and is characterized by behavioral control.

Responsiveness refers to a parent's recognition of a child's individuality and autonomy and is characterized by warmth and supportiveness.

Considering that parenting style is expressed through various parenting practices (Darling and Steinberg, 1993), parental mediation is likely to be one of the many behaviors influenced by parenting style. However, only a few studies have examined its role in parental mediation. For example, Carlson and Grossbart (1988) demonstrated that parents high on both demandingness and responsiveness controlled children's television viewing and discussed advertising with children more than parents high on only one or neither of the dimensions. In the context of internet use, Eastin et al. (2006) found that active mediation and co-surfing were most frequently practiced by parents high on both demandingness and responsiveness. Broadening the context to both traditional and new media (i.e., television and the internet), Padilla-Walker and Coyne (2011) showed that parents high on warmth and support (termed "connection"), as well as parents high on behavioral control through inductive reasoning (termed "regulation"), were more likely to engage in active mediation of children's media use.

In addition to parenting style, parental involvement with children also has the potential to influence the degree to which parents engage in media mediation. Parental involvement is 
assessed by the degree to which parents make themselves available to engage in shared activities with their children (Warren, 2005). Parental involvement differs from parenting style in that the former regards the activities that parents engage to interact with their children whereas the latter refers to general childrearing tendencies demonstrating control and warmth with their children in various parent-child interactions (Warren, 2005). Studies demonstrated that parent-child interaction varies across different parent-child pairs (Baumrind, 1971; Darling \& Steinberg, 1993). That is, some parents interact with their children more often, while others maintain distance from their children. A few parental mediation studies focused on children's television viewing have demonstrated meaningful associations between parental involvement and parental mediation. Through a series of studies with different age and income groups of children and parents, Warren $(2001,2002,2005)$ demonstrated that parental involvement, measured by the number of hours parents spent with their children and the number of activities that parents shared with children, was significantly associated with parental mediation of children's television viewing.

Overall, the literature suggests that the level and type of mediation that parents use can be influenced by a wide range of factors. That is, although parental mediation may decrease the negative effects of digital technology for children, the types and extent of mediation depend strongly on the parent. The literature also suggests that parents' perception and usage of media, as well parent-child interaction patterns, play more important roles than parent-child demographic characteristics. Thus, the present study investigates parents' digital technology perception and usage and parent-child interaction patterns as main effect variables influencing parental mediation, while examining the aforementioned parent-child individual characteristics as control variables. 
RQ2. How are (1) parents' perception and usage of digital technology and (2) parent-child interaction patterns associated with different types of parental mediation applied to children's digital technology use, controlling for parent-child individual characteristics?

\section{Method}

\section{Sample and Procedure}

Data were collected from parents of children in grades 1 through 6 recruited from seven public primary schools located in various parts of Singapore to represent diverse socio-economic and geographic segments of children in the country. The Heads of Departments of each participating school selected two upper primary (grades 4-6) and two lower primary (grades 1-3) classes in which to distribute the questionnaire. A paper-and-pencil survey questionnaire was then administered to parents through their children in the selected classes. A total of 972 survey questionnaires were distributed and 557 valid responses were received, giving a response rate of $57 \%$.

\section{Survey Instrument and Measures}

The questionnaire began with an explanation of the purpose of the study, and each question was accompanied by an instruction. The questionnaire first stated that "digital technology" referred to computers, tablets, and smartphones and provided the definition of each digital device. The survey also stated that "your child" in the questionnaire referred to the child who had brought the questionnaire home. The questionnaire included the following measures.

Parental mediation. Measurement items were constructed based on a review of previous literature on parental mediation of children's internet use and video game playing (e.g., Lee \& Chae, 2012; Livingstone, Haddon, Gorzig, \& Olafsson, 2011; Livingstone \& Helsper, 2008; Nikken \& Jansz, 2006; Nikken \& Jansz, 2014). The items used in this study were modified to 
reflect types of parental mediation directly relevant to digital technology. We focused on three forms of parental mediation - active mediation, restrictive mediation, and monitoring. Active mediation was assessed by asking parents how they guide their child in the use of digital technology. Restrictive mediation was assessed by asking parents how they regulate their child's use of digital technology. While we assessed both active and restrictive mediation in this study as both are known to be practiced in both traditional and digital media contexts, this study did not assess co-use, as co-use is less likely to occur due to the nature of digital technology. Digital technology use is mostly a solitary activity, typically involving a personal and mobile device (Livingstone \& Helsper, 2008; Nikken \& Jansz, 2006). As an alternative to co-use, we measured parents' monitoring of children's digital technology use by asking parents how they monitor their child when the child is using digital technology. Each of the parental mediation styles was measured using five binary scale items $(1=$ yes; $0=$ no). The number of "yes" (1) responses for each type of parental mediation was summed to form composite scales for active mediation, restrictive mediation, and monitoring. Measurement items are presented in Figures 1, 2, and 3.

Time spent on digital technology. Using 5-point scales, anchored by "no usage" (1), "less than 1 hour a day" (2), "1 hour a day" (3)," 2-3 hours a day" (4), and "4 hours and above” (5), parents were asked to indicate how much time per day they usually spent using digital technology at home on a computer $(M=1.98, S D=1.26)$, tablet $(M=1.56, S D=1.30)$, and smartphone $(M=2.54, S D=1.23)$. Item scores were summated to form a composite scale.

Digital technology activities. Parents were asked to indicate for what purpose they usually use digital technology using 7 binary scale items: job-related tasks, household tasks, social media, educational purposes, leisure, personal communication, and other. The number of "yes" (1) responses was summed to form a composite scale $(M=4.20, S D=1.62)$. 
Attitude toward digital technology. Parents were asked to rate their attitude toward digital technology, using six 5-point semantic differential scales (bad/good, not interesting/interesting, harmful/beneficial, not fun to use/fun to use, not useful/useful, and uninformative/informative). The items were adapted from research on attitudes toward advertising (Muehling, 1987). Item scores were averaged to create a composite scale $(M=3.98, S D=.68, \alpha=.87)$.

Parenting styles. Parents were asked to report their parenting styles using six 5-point Likert scales ( $1=$ strongly disagree; $5=$ strongly agree $)$. The items were adapted from the Parenting Style Index developed by Steinberg et al. (1992). Three items measured parental demandingness (e.g., "My child should come home by the time that I set") and three items measured parental responsiveness (e.g., "When I want my child to do something, I explain why"). An exploratory factor analysis confirmed the internal structure of the measurement, yielding two factors for demandingness and responsiveness. Item scores were averaged to create composite scales for demandingness $(M=3.95, S D=.61, \alpha=.62)$ and responsiveness $(M=4.28$, $S D=.59, \alpha=.77)$

Parental involvement. Parents were asked to indicate the number of times per week they engaged in various activities with their child using 5-point scales, anchored by "none" (1), "1 to 2 times" (2), "3 to 4 times" (3), "5 to 6 times" (4), and "7 times or more" (5). The measurement items were derived from Warren et al.'s (2002) parental involvement scales and included the following five items: household chores, face-to-face conversations, indoor entertainment, outdoor activities, and meals. Item scores were averaged to create a composite scale $(M=2.32$, $S D=.73, \alpha=.68)$.

The questionnaire collected information about the child's age and gender $(1=$ boy; $2=$ girl $)$ and the parent's age, gender $(1=$ male; $2=$ female $)$, and education level $(1=\mathrm{O}$ level or 
equivalent $\&$ below; $2=$ A level, diploma or equivalent; $3=$ Bachelor's degree; $4=$ postgraduate). Parents were also asked to indicate to what extent they think parents/guardians influence their child's digital technology use, using a single ad-hoc item ranging from "not at all influential" (1) to "extremely influential" (5) $(M=3.48, S D=1.02)$.

\section{Results}

The final sample $(N=557)$ consisted of $61.5 \%$ female parents/guardians, and the average age was $41.76(\mathrm{SD}=5.71)$. Four out of ten $(42.3 \%)$ had college degrees. Fifty-five percent of them were parents of boys, and 52\% were parents of children age 9 and older $(M=9.54, S D=$ 1.68). Eight in ten parents (83.0\%) used computers, $63.5 \%$ used tablets, and $91.2 \%$ used smartphones at home. Digital technology was used for various purposes: personal communication (84.4\%), leisure (80.1\%), education (79.0\%), social media (74.7\%), job-related tasks (65.7\%), household tasks (28.4\%), and other (7.5\%).

RQ1 asked what parents do to mediate children's digital technology use. Overall, restrictive mediation $(M=3.06, S D=1.42)$ and active mediation $(M=2.94, S D=1.53)$ were more prevalent than monitoring $(M=2.16, S D=1.28)$. Inter-correlations between the active mediation items were significant and positive except for the relationship between "explain why digital technology is good or bad" and "help whey the child is using digital technology." All restrictive mediation items were significantly and positively correlated with each other. With regard to monitoring, most of the inter-correlations were significant and positive, except "ask what your child is doing" which was not significantly associated with "keep an eye on the screen of the device," as well as "stay in the same room as your child."

A breakdown of the prevalence of these strategies is illustrated in Figures 1 to 3. With regard to active mediation, the most popular strategies were talking to children about what 
should or should not be shared on the internet (67.0\%) and explaining why digital technology is either good or bad (61.8\%). The least popular active mediation strategy among parents was recommending good digital content to their children $(52.4 \%)$. With regard to restrictive mediation, the most popular strategy was limiting the time that children spent using digital technology $(76.1 \%)$, followed by allowing children to use digital technology only after designated tasks such as homework or household chores had been completed (73.1\%). The least popular strategy was to limit the child's sharing of personal information or communication with others online $(49.2 \%)$. With regard to monitoring, the most popular strategy was asking the child what he or she was doing $(80.4 \%)$, followed by keeping an eye on the device's screen $(53.5 \%)$. Only two to three out of every ten parents reported that they sat with their child $(24.4 \%)$, stayed in the same room with the child $(29.8 \%)$, or checked the digital devices later $(28.2 \%)$ to monitor the child's digital technology use.

\section{Figures 1, 2, 3 are about here}

RQ2 asked how different sets of factors (parents' perception and usage of digital technology and parent-child interaction) are associated with different mediation strategies, controlling for parent-child individual characteristics. To test this research question, three separate hierarchical regression analyses were conducted, with the three parental mediation strategies as dependent variables. For each analysis, control variables were entered into the first block, followed by parents' digital technology attitude and usage (block 2), and parent-child interaction patterns (block 3). Before conducting the regression analyses, we calculated bivariate correlations among the examined variable to detect multicollinearity in the dataset. None of the variables were found to be strongly correlated (i.e., $r>$.70) (Howell, 2002). We also obtained 
collinearity statistics (tolerance and variance inflation factors) when we ran the regression analyses. No issue of multicollinearity arose. Table 1 presents the results.

\section{Table 1 is about here}

Control variables explained $6 \%$ of the total variance in active mediation. This increased to $12 \%$ with the inclusion of parents' usage and perception of digital technology in the second step, and went up to $16 \%$ when parent-child interaction was added in the third step. The regression model indicates that parents who engage in more diverse digital technology activities $(\beta=.20, p<.001)$ and spend more time on shared activities with their child $(\beta=.14, p<.01)$ with a responsive parenting style $(\beta=.12, p<.01)$ are more likely to engage in active mediation.

With regard to restrictive mediation, control variables similarly explained $5 \%$ of the total variance in restrictive mediation. After the inclusion of parents' usage and perception of digital technology in the second step, this went up to $15 \%$. In the third step that included parent-child interaction, this increased to $19 \%$. Diversity of digital technology activities $(\beta=.32, p<.001)$ and responsiveness $(\beta=.13, p<.01)$ significantly predicted restrictive mediation. However, parental involvement was not found to be associated with restrictive mediation.

For monitoring, control variables explained 3\% of the total variance. Adding parents' usage and perception of digital technology factors in the second step resulted in an increase to $7 \%$, while including parent-child interaction factors in the third step resulted in an increase to $11 \%$. Diversity of digital technology activities showed a significant relationship with monitoring $(\beta=.15, p<.001)$. Parental involvement significantly predicted monitoring $(\beta=.12, p<.01)$, whereas demandingness and responsiveness were not significantly associated with monitoring.

Time spent on digital technology, attitude toward digital technology, and demandingness were not associated with any of the parental mediation styles examined. Among the control 
variables, none of the parent-child demographic variables were found to be associated with any pf the parental mediation, while the degree to which parents perceived themselves as an important influencer of children's digital technology use was positively associated with both active mediation $(\beta=.15, p<.001)$ and restrictive mediation $(\beta=.09, p<.05)$.

\section{Discussion}

As digital natives, children today are tech-savvy and often use multiple types of digital media concurrently. In response to the changing media environment and media consumption trends among children, this study examined parental mediation with regard to children's media usage across multiple digital devices in Singapore, a non-Western city-state with high levels of technology penetration and usage. Specifically, this study set out to investigate (1) the extent to which parents handle children's use of and exposure to digital technology and (2) factors that are associated with parents' behavior.

Regarding the types of parental mediation employed by parents to manage children's use of digital technology, our findings revealed that parents in Singapore focus on some aspects of digital technology more than other aspects. Specifically, while parents often talk to their children about good and bad aspects of digital technology, they are less likely to recommend good digital technology content to their children. Parents often impose time restrictions on digital technology use, but they are less likely to limit children's engagement in online communication and information sharing. To monitor children's digital technology use, parents often ask their child what he or she is doing with digital devices or keep an eye on the device screens. However, they are less likely to stay in the same room or check the devices or accounts later to determine past activities. 
Overall, it appears that parents prefer simpler and more straightforward forms of parental mediation. Many of the parental mediation strategies popular among parents in this study (e.g., talking to children about good and bad aspects of digital technology, imposing time restrictions, asking children what they do with digital devices, and keeping an eye on them) seem to be relatively easier to implement than less popular types (e.g., recommending good digital content, limiting communication and information sharing, and checking digital technology activities). In fact, it appears that implementing the less popular strategies would require more time and effort, as well as extensive knowledge of digital technology.

Due to the high cost of living in Singapore, there is a high percentage of families where both parents are working. These factors, together with a cultural pressure to provide the best for their children, has led to Singapore having the lowest fertility rate in the world (Central Intelligence Agency, 2016). As a result, for Singapore's busy parents, closely monitoring children's digital activities or making recommendations of specific digital content can be fairly challenging, and perhaps the aforementioned simpler, more popular mediation strategies might be reasonable solutions for parents to deal with children's active engagement in digital technology. However, for today's tech-savvy children, who are born into a world of digital technology, these general and easy-to-implement approaches may be insufficient. Instead, more specific and focused discussion and supervision may result in better outcomes. For instance, Radanielina-Hita (2014) found that parents' critiques of media portrayals led to a higher level of critical thinking among children. Future research could examine the effects and effectiveness of each strategy within each domain of parental mediation (e.g., talking about positive and negative aspects of media vs. recommending specific content under the active mediation domain) rather than simply treating all the different strategies as a single composite construct (e.g., "active 
mediation" as a whole), although we acknowledge that composite scales have their own utility and provide useful insights in some contexts.

It should also be noted that our study did not test whether parents perceive certain types of parental mediation strategies to be more or less challenging. Therefore, we call for caution when interpreting our findings. An alternative explanation for our findings could be that parents deem some mediation strategies to be less necessary than others. For instance, when a parent often talks with his/her child about what the child is doing online, the parent talks about what should be shared online, and explains the good and bad sides of technology, it may be less necessary for the parent to specifically recommend good content. Our study was interested in the influence of individual characteristics and family interaction on parental mediation. With regard to psychological antecedents such as motivations behind parental mediation strategies, we suggest future studies explore the significance and rationale behind the more or less popular strategies among Singaporean parents. Qualitative research methods such as in-depth interviews or focus group discussions can be adopted to explore the rationales and motivations for parental mediation strategies employed by parents.

We also examined how different factors are associated with parental mediation of children's digital technology use. We found nonexistent relationships between parent-child demographic characteristics and mediation styles. Instead, our findings indicate that parents' usage of digital technology and parent-child interaction factors are more important in how parents practice mediation. This finding is in line with prior studies demonstrating that demographic variables alone cannot sufficiently explain how parents mediate children's use of media, especially when other parental factors such as parents' views and usage of media and 
parent-child relationships are considered (Sonck et al., 2013; Valkenburg et al., 1999; Warren et al., 2002).

Scholars have suggested that parents' media competency plays an important role in explaining the levels and types of parental mediation (Livingstone \& Helsper, 2008; Sonck et al., 2013). However, little is known about how parents' own media consumption behavior affects parental mediation of child's digital technology use. Our results indicate that parental mediation is more a function of the diversity of technology activities rather than time spent on digital technology. This seems to suggest that greater knowledge of digital technology and a higher engagement these activities influence parental mediation strategies more than just the quantity of time spent on digital devices. As suggested by Sonck et al. (2013), the more types of digital activities parents engage in, the more they may understand and know the issues and problems that their child might face when using digital technology. Future research is encouraged to investigate the relationship between parents' use of digital technology and their knowledge of digital media in relation to parental mediation types and effects.

With regards to the role of parental attitudes toward digital technology, we found no association between attitude toward technology and mediation styles. Instead, perceived parental influence, which was tested as a control variable, emerged as a significant predictor of active mediation and was found to be directionally associated with restrictive mediation. The results seem to suggest that parental mediation, especially communication-based active mediation, is more a function of parental perception in relation to their children's media usage rather than parents' own perception of the media in general. An interesting finding is that perceived parental influence is significantly and strongly $(p<.001)$ associated with active mediation, but it is weakly associated with restrictive mediation $(p<.05)$ and not significantly associated with 
monitoring $(p>.05)$. When parents feel confident that their influence has a positive impact, they may be motivated to engage in more hands-on, directive mediation — talking to children about digital technology or helping them when they are using digital technology. This can be explained by the concept of self-efficacy (Bandura \& Schunk, 1981), where self-confidence in a behavior can lead one to effectively carry it out. High self-efficacy leads to an individual putting in greater effort to achieve goals, and this results in the individual being more motivated to carry on with the behavior despite obstacles or barriers. However, if parents do not feel that they can impact their children, they may engage in less hands-on and more passive types of parental mediationsetting rules (i.e., restrictive mediation) or keeping an eye on screens (i.e., monitoring) without providing specific directives.

Some of the parent-child interaction factors were found to have significant effects on parental mediation. Active mediation was predicted by both responsiveness and parental involvement (measured as the amount of time spent on shared activities), implying that active mediation reflects parents' warmth and supportiveness with their children as well as their behavioral engagement in shared activities (e.g., communication). Restrictive mediation was significantly associated with responsiveness but not with parental involvement. On the other hand, monitoring was significantly associated with parental involvement but not with responsiveness. Perhaps monitoring is easy for parents to adopt when they are spending time together and engaging in common activities. Connell, Lauricella, and Wartella (2015) found that the amount of time parents spend with their child predicts media co-use. Such a scenario appears to be applicable to monitoring, as engaging in common activities can easily allow parents to observe what the child is doing on digital devices. 
This study has several limitations. First, the data reflect parents' point of view only. Research suggests that parents tend to overestimate their control over their children, and that findings based on parent reports can be vulnerable to a social desirability and self-serving biases (Liau, Khoo, \& Ang, 2008). To gain more accurate and balanced insights which take into account both parents and children's perspectives, future research should look not only at parents' self-report on their parental mediation strategies, but the presence and influence of these strategies from the children's angle. In addition, although we tried to examine a wide range of parental factors as potential predictors of parental mediation of children's digital technology use, other important factors could also be examined in future research, such as family communication patterns (McLeod \& Chaffee, 1972) and parents' perceived and actual knowledge and skills with regard to digital technology (Livingstone \& Helsper, 2008). Another methodological limitation of this study is that parental mediation was measured on dichotomous scales. While it allows us to access the overall tendencies to adopt mediation strategies, we were not able to tease out the inclination intensity towards specific mediation methods. Future research might replicate this study using rating scales (e.g., Likert scale) to assess the variance in parents' responses to each measurement item. Finally, the goal of this study was to examine parental mediation of overall digital screen time, and it was based on the fact that today's children use multiple digital media at the same time. Still, one could gain more comprehensive and useful insights if parental mediation of each type of digital technology were examined. Future research will provide a more complete picture of today's media landscape if children's use of traditional media is also considered.

Despite the limitations, this research examines timely and important but underexplored issues (i.e., children's digital technology use), with potential contributions to the body of parental 
mediation literature. Extensive research on parental mediation has examined how parents influence children's use of media and factors influencing it. However, most prior studies have focused on parental mediation of a single type of media activity, such as television viewing, video game playing, or the internet usage. Our study not only examined how parents implement parental mediation, it also investigated and identified various factors accounting for parents' involvement in parental mediation in the changing media environment. We hope our findings provide communication scholars, parents, and educators with useful insights.

This study serves as a pioneer effort to disclose what non-western parents do and think of parental mediation of children's use of digital technologies. Results from the study are especially useful in the context of Singapore and similar countries where most children have access to the internet either at home or in school, and where mobile phone penetration rates are constantly increasing. The high cost and high standard of living in the city-state have resulted in many dualincome families where both parents work, making it difficult for parents to take time to hone their knowledge of digital technology and implement more hands-on, directive types of parental mediation for their tech-savvy children. For policy makers, our finding (i.e., parents rely more on simple-to-implement mediation strategies) may be useful for the development of educational programs and guidelines for parents. The findings here also suggest that parental mediation is a function of various parental factors. With the government taking an active interest in safeguarding "digital kids," we suggest that parental factors be considered in the implementation of digital-technology policies and campaigns targeted to children. 


\section{References}

theAsianparent Insights (2014). Mobile Device Usage Among Young Kids: A South Asia Study. Retrieved May 9, 2015, from https://s3-ap-southeast-1.amazonaws.com/tap-sgmedia/theAsianparent+Insights+Device+Usage+A+Southeast+Asia+Study+November+20 14.pdf

Austin, E. W., Bolls, P., Fujioka, Y., \& Engelbertson, J. (1999). How and why parents take on the tube. Journal of Broadcasting \& Electronic Media, 43(2), 175-192.

Bandura, A., \& Schunk, D. H. (1981). Cultivating competence, self-efficacy, and intrinsic interest through proximal self-motivation. Journal of Personality and Social Psychology, 41, 586-596.

Baumrind, D. (1971). Current patterns of parental authority. Developmental Psychology, 4(1p2), 1.

Bugental, D. B., \& Grusec, J. E. (2006). Socialization Theory. In N. Eisenberg (Vol. Ed.), Handbook of child psychology: Vol. 3. Social, emotional, and personality development (pp. 366 -428). New York: Wiley.

Buijzen, M., \& Valkenburg, P. M. (2005). Parental mediation of undesired advertising effects. Journal of Broadcasting \& Electronic Media, 49(2), 153-165.

Carlson, L., \& Grossbart, S. (1988). Parental style and consumer socialization of children. Journal of Consumer Research, 77-94.

Central Intelligence Agency. (2016). The World Factbook. Retrieved April 11, 2016, from https://www.cia.gov/library/publications/the-world-factbook/rankorder/2127rank.html

Chang, W. C., Wong, W. K., \& Koh, J. B. K. (2003). Chinese values in Singapore: Traditional and modern. Asian Journal of Social Psychology, 6(1), 5-29.

Clark, L. S. (2011). Parental mediation theory for the digital age. Communication Theory, 21(4), 323-343.

Connell, S. L., Lauricella, A. R., \& Wartella, E. (2015). Parental co-use of media technology with their young children in the USA. Journal of Children and Media, 9(1), 5-21.

Consumer Barometer (2014). The Consumer Barometer. Retrieved May 9, 2015, from https://www.consumerbarometer.com/en/insights/?countryCode=SG

Darling, N., \& Steinberg, L. (1993). Parenting style as context: An integrative model. Psychological Bulletin, 113(3), 487.

Eastin, M. S., Greenberg, B. S., \& Hofschire, L. (2006). Parenting the internet. Journal of Communication, 56(3), 486-504. 
Fujioka, Y., \& Austin, E. W. (2002). The relationship of family communication patterns to parental mediation styles. Communication Research, 29(6), 642-665.

Gentile, D. A., Riemer, R., Nathanson, A., Walsh, D., \& Elsenmann, J. (2014). Protective effects of paretnal monitoring of children's media use: A prospective study. JAMA Pediatrics, published online Marth 31, 2014.

Grusec, J. E., \& Davidov, M. (2007). Socialization in the family. In J. E. Grusec, \& P. D. Hastings (Eds.), Handbook of socialization: Theory and Research (pp. 284-308). New York: Guilford.

Gutnick, A. L., Robb, M., Takeuchi, L., \& Kotler, J. (2010). Always Connected: The New Digital Media Habits of Young Children. New York: Sesame Workshop and the Joan Ganz Cooney Center.

Howell, D. C. (2002). Statistical Methods for Psychology. Pacific Gove, CA: Duxbury.

Hoffner, C., \& Buchanan, M. (2002). Parents' responses to television violence: The third-person perception, parental mediation, and support for censorship. Media Psychology, 4(3), 231252.

Infocomm Development Authority of Singapore. (2015). Telecommunications. Retrieved March 10, 2015, from http://www.ida.gov.sg/Tech-Scene-News/Facts-andFigures/Telecommunications\#1

John, D. R. (1999). Consumer socialization of children: A retrospective look at twenty-five years of research. Journal of Consumer Research, 26(3), 183-213.

Khurana, A., Bleakley, A., Jordan, A., \& Romer, D. (2015). The protective effects of parental monitoring and internet restriction on adolescents' risk of online harassment. Journal of Youth and Adolescence, 44(5), 1039-1047.

Kirwil, L. (2009). Parental mediation of children's internet use in different European countries. Journal of Children and Media, 3(4), 394-409.

Lee, S. J. (2013). Parental restrictive mediation of children's internet use: Effective for what and for whom? New Media \& Society, 15(4), 466-481.

Lee, S. J., \& Chae, Y. G. (2007). Children's internet use in a family context: Influence on family relationships and parental mediation. CyberPsychology \& Behavior, 10(5), 640-644.

Liau, A. K., Khoo, A., \& Ang, P. H. (2008). Parental awareness and monitoring of adolescent internet use. Current Psychology, 27(4), 217-233.

Livingstone, S., Haddon, L., Gorzig, A., \& Olafsson, K. (2011). EU Kids Online (September 2011). Retrieved June 6, 2014, from 
http://www.lse.ac.uk/media\%401se/research/EUKidsOnline/EU\%20Kids\%20II\%20(200911)/EUKidsOnlineIIReports/Final\%20report.pdf

Livingstone, S., \& Helsper, E. J. (2008). Parental mediation of children's internet use. Journal of Broadcasting \& Electronic Media, 52(4), 581-599.

Lwin, M. O., Stanaland, A. J., \& Miyazaki, A. D. (2008). Protecting children's privacy online: How parental mediation strategies affect website safeguard effectiveness. Journal of Retailing, 84(2), 205-217.

McLeod, J. M., \& Chaffee, S. H. (1972). The construction of social reality. In J. Tedeschi (Ed.), The social influence processes (pp. 50-99). Chicago: Aldine.

Ministry of Education. (2013a). About the Inter-Ministry Cyber Wellness Steering Committee (ICSC). Retrieved May 9, 2015, from http://www.moe.gov.sg/events/2013/cyber-wellnesscall-for-proposals/about-us/

Ministry of Education. (2013b). Children look within to become 'iZ Heroes' to tackle 'infollution'! Retrieved May 9, 2015, from

http://www.moe.gov.sg/media/press/2013/05/children-look-within-to-become-iz-heroes-totackle-infollution.php

Ministry of Education. (2014). Launch of C-Quest: A mobile app game to promote conversations about cyber wellness between parents and children. Retrieved May 9, 2015, from http://www.moe.gov.sg/media/press/2014/09/launch-of-c-quest-a-mobile-app-game-topromote-conversations-about-cyber-wellness-between-parents-and-children.php

Muehling, D. D. (1987). An investigation of factors underlying attitudes-towards-advertising-ingeneral. Journal of Advertising, 16(1), 32-40.

Nathanson, A. I. (2001). Parent and child perspectives on the presence and meaning of parental television mediation. Journal of Broadcasting \& Electronic Media, 45(2), 201-220.

Nathanson, A. I. (2002). The unintended effects of parental mediation of television on adolescents. Media Psychology, 4, 207-230.

Nielsen. (2014). The Asian Mobile Consumer Decoded. Retrieved April 11, 2016, from http://www.nielsen.com/ph/en/insights/news/2014/asian-mobile-consumers.html

Nielsen. (2015). Q1 2015 Local watch report: Where you live and its impact on your choices. Retrieved April 11, 2016, from http://www.nielsen.com/us/en/insights/reports/2015/q12015-local-watch-report-where-you-live-and-its-impact-on-your-choices.html

Nikken, P., \& Jansz, J. (2006). Parental mediation of children's videogame playing: A comparison of the reports by parents and children. Learning, Media and Technology, 31(2), 181-202. 
Nikken, P., Jansz, J., \& Schouwstra, S. (2007). Parents' interest in videogame ratings and content descriptors in relation to game mediation. European Journal of Communication, 22(3), 315-336.

Nikken, P., \& Jansz, J. (2014). Developing scales to measure parental mediation of young children's internet use. Learning, Media and Technology, 39(2), 250-266.

Ofcom. (2014). The Communications Market Report. Retrieved March 19, 2015, from http://stakeholders.ofcom.org.uk/binaries/research/cmr/cmr14/2014_UK_CMR.pdf

Padilla-Walker, L. M., \& Coyne, S. M. (2011). “Turn that thing off!” parent and adolescent predictors of proactive media monitoring. Journal of Adolescence, 34(4), 705-715.

Pearce, K. E., \& Rice, R. E. (2013). Digital divides from access to activities: Comparing mobile and personal computer internet users. Journal of Communication, 63(4), 721-744.

Radanielina-Hita, M. L. (2014). Parental mediation of media messages does matter: More interaction about objectionable content is associated with emerging adults' sexual attitudes and behaviors. Health Communication, 30(8), 784-798.

Rideout, V. J. (2013). Zero to Eight: Children's Media Use in America 2013. San Francisco, CA: Common Sense Media.

Shin, W., \& Huh, J. (2011). Parental mediation of teenagers' video game playing: Antecedents and consequences. New Media \& Society, 13(60), 945-962.

Shin, W., Huh, J., \& Faber, R. J. (2012). Tweens' online privacy risks and the role of parental mediation. Journal of Broadcasting \& Electronic Media, 56(4), 632-649.

Shin, W., \& Ismail, N. (2014). Exploring the role of parents and peers in young adolescents' risk taking on social networking sites. Cyberpsychology, Behavior, and Social Networking, 17(9), 578-583.

Smith, P. B., Dugan, S., \& Trompenaars, F. (1996). National culture and the values of organizational employees a dimensional analysis across 43 nations. Journal of crosscultural psychology, 27(2), 231-264.

Sonck, N., Nikken, P., \& de Haan, J. (2013). Determinants of internet mediation: A comparison of the reports by Dutch parents and children. Journal of Children and Media, 7(1), 96-113.

Steinberg, L., Lamborn, S. D., Dornbusch, S. M., \& Darling, N. (1992). Impact of parenting practices on adolescent achievement: Authoritative parenting, school involvement, and encouragement to succeed. Child Development, 63(5), 1266-1281.

Trend Micro (2014). 3 in 4 internet users in Singapore are concerned about privacy on social networks; Trend Micro launches software to reduce vulnerabilities. Retrieved March 19, 
2015, ttp://www.trendmicro.com.sg/sg/aboutus/newsroom/releases/articles/20140918062117.html

Tufte, B., \& Rasmussen, J. (2010). Children and the Internet. In D. Marshall (Ed.), Understanding Children as Consumers (pp. 184-201). Los Angeles: Sage.

Valkenburg, P. M., Krcmar, M., Peeters, A. L., \& Marseille, N. M. (1999). Developing a scale to assess three styles of television mediation: "Instructive mediation," "restrictive mediation," and "social coviewing". Journal of Broadcasting \& Electronic Media, 43(1), 52-66.

Warren, R. (2001). In words and deeds: Parental involvement and mediation of children's television viewing. The Journal of Family Communication, 1(4), 211-231.

Warren, R. (2002). Preaching to the Choir? Parents' Use of TV Ratings to Mediate Children's Viewing. Journalism \& Mass Communication Quarterly, 79(4), 867-886.

Warren, R. (2005). Parental mediation of children's television viewing in low-income families. Journal of Communication, 55(4), 847-863.

Warren, R., Gerke, P., \& Kelly, M. A. (2002). Is there enough time on the clock? Parental involvement and mediation of children's television viewing. Journal of Broadcasting \& Electronic Media, 46(1), 87-111.

Wartella, E., Rideout, V., Lauricella, A. R., \& Connell, S. (2013). Parenting in the age of digital technology. Report for the Center on Media and Human Development School of Communication Northwestern University.

We Are Social (2015). Digital, Social \& Mobile in 2015. Retrieved March 19, 2015, from http://wearesocial.sg/blog/2015/01/digital-social-mobile-2015/

World Economic Forum (2014). The Global Information Technology Report 2014. Retrieved March 19, 2015, from http://www3.weforum.org/docs/WEF_GlobalInformationTechnology_Report_2014.pdf

World Economic Forum (2015). The Global Competitiveness Report: 2015-2016. Geneva, Switzerland. Retrieved April 11, 2016, from http://www3.weforum.org/docs/gcr/20152016/Global_Competitiveness_Report_2015-2016.pdf 
Figure 1. Types of Active Mediation (\%)

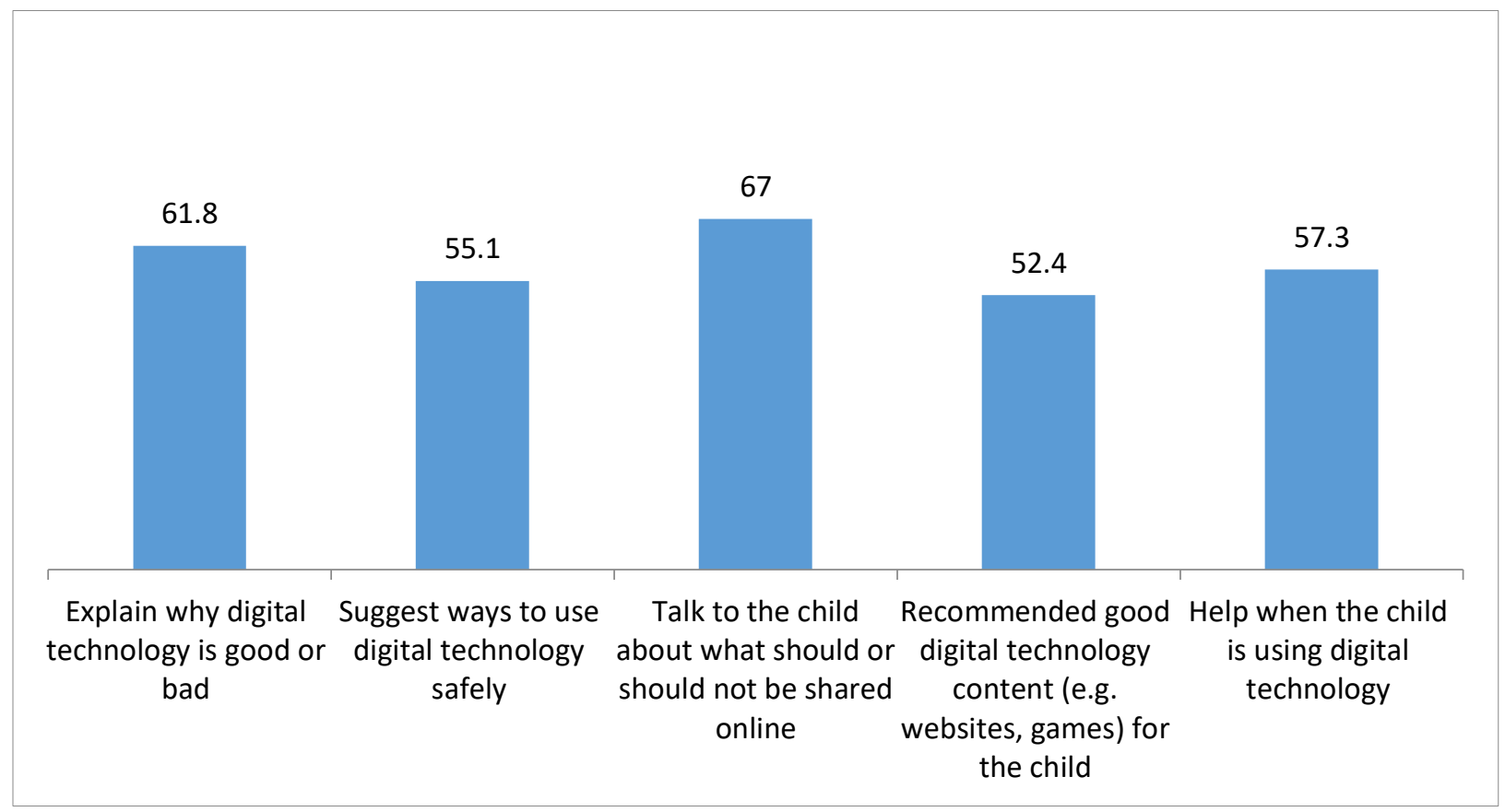


Figure 2. Types of Restrictive Mediation (\%)

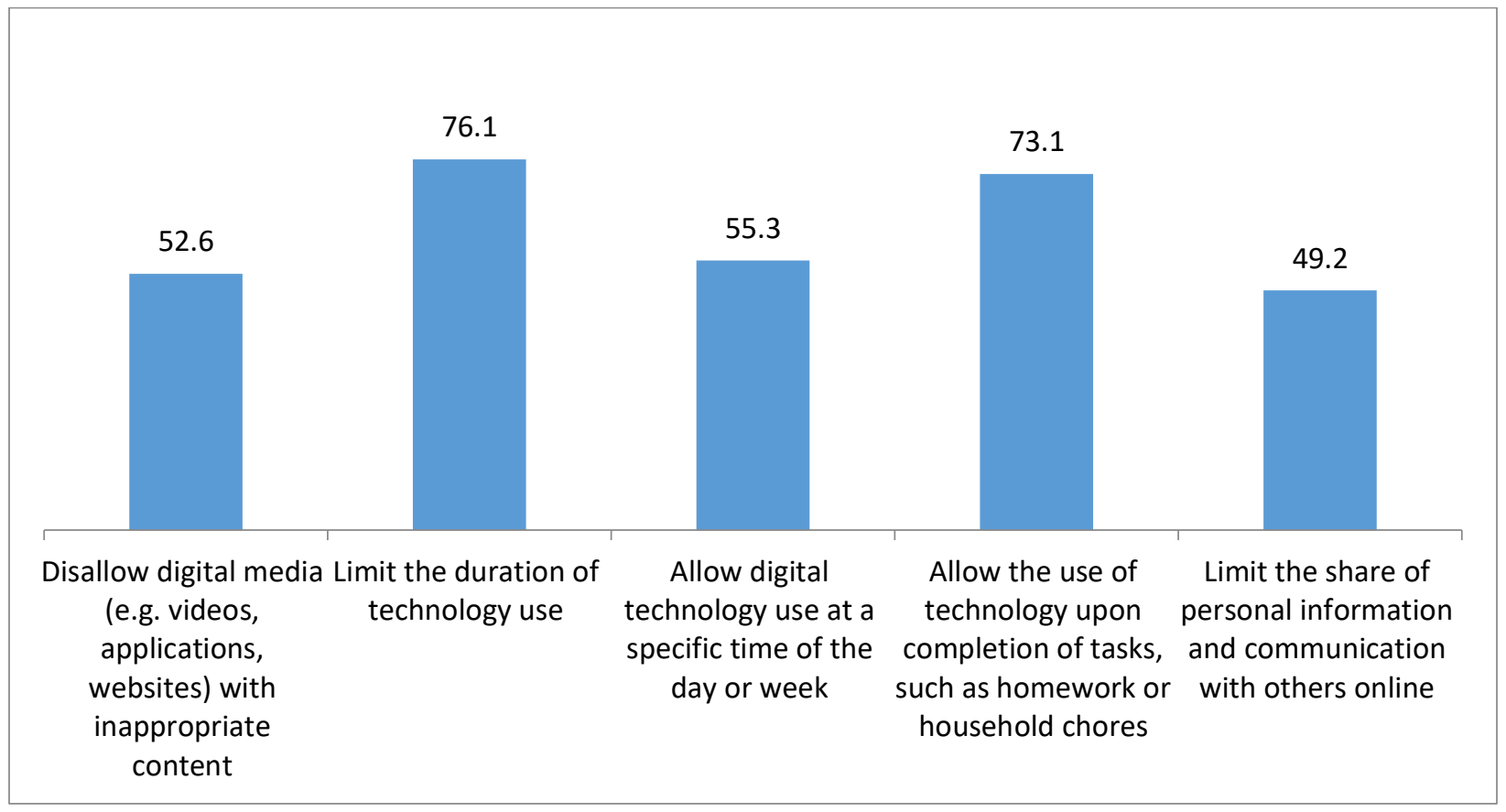


Figure 3. Types of Monitoring (\%)

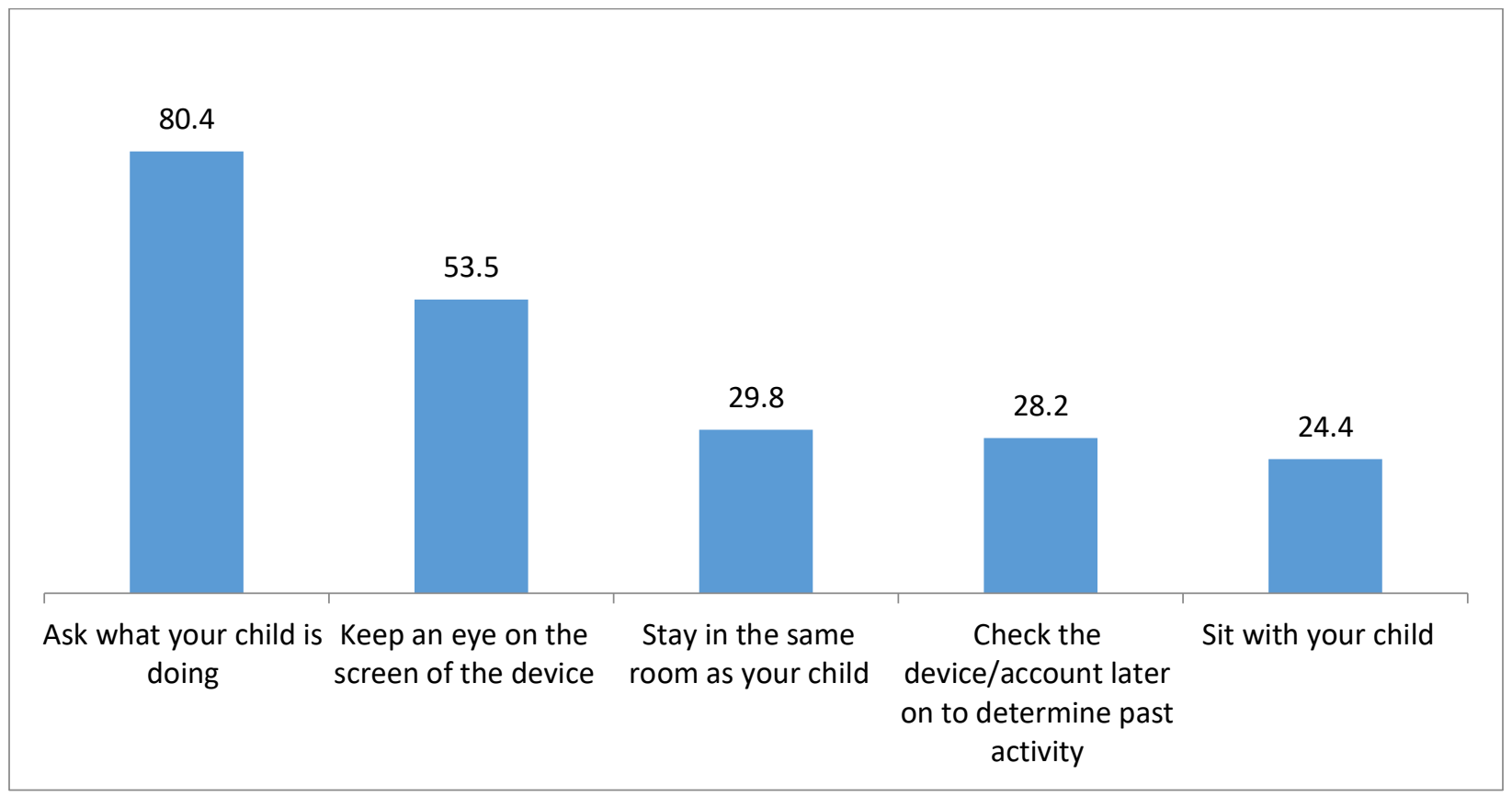


Table 1. Hierarchical Regression for Predicting Parental Mediation $(\beta)$

\begin{tabular}{|c|c|c|c|}
\hline & Active mediation & Restrictive mediation & Monitoring \\
\hline \multicolumn{4}{|l|}{ Block 1: Control variables } \\
\hline Child's age & .05 & .05 & -.05 \\
\hline Child's gender & -.01 & -.02 & -.03 \\
\hline Parent's age & -.06 & .03 & -.07 \\
\hline Parent's gender & -.03 & .03 & -.03 \\
\hline Parent' education & -.08 & -.02 & -.04 \\
\hline \multirow{2}{*}{$\begin{array}{l}\text { Perceived influence of parents on } \\
\text { children's technology use }\end{array}$} & $.15^{* * *}$ & $.09 *$ & .03 \\
\hline & $\begin{array}{c}R^{2}=.06 \\
F(6,550)=6.13 \\
p<.001\end{array}$ & $\begin{array}{c}R^{2}=.05 \\
F(6,550)=4.50 \\
p<.001\end{array}$ & $\begin{array}{c}R^{2}=.03 \\
F(6,550)=3.02 \\
p<.001\end{array}$ \\
\hline \multicolumn{4}{|l|}{$\begin{array}{l}\text { Block 2: Parents' usage and } \\
\text { perceptions of digital technology }\end{array}$} \\
\hline Time spent on digital technology & .02 & -.04 & .03 \\
\hline Digital technology activities & $.20 * * *$ & $.32 * * *$ & $.15 * * *$ \\
\hline \multirow[t]{3}{*}{ Attitude toward digital technology } & -.03 & -.04 & .03 \\
\hline & $R^{2}=.12 * * *$ & $R^{2}=.15^{* * *}$ & $R^{2}=.07 * * *$ \\
\hline & $F(9,547)=.8 .30$ & $F(9,547)=10.38$ & $F(9,547)=4.75$ \\
\hline \multicolumn{4}{|l|}{ Block 3: Parent-child interaction } \\
\hline Demandingness & .05 & .08 & .09 \\
\hline Responsiveness & $.12 * *$ & $.13 * *$ & .09 \\
\hline \multirow{3}{*}{ Parental involvement } & $.14 * *$ & .08 & $.12 * *$ \\
\hline & $R^{2}=.16^{* * *}$ & $R^{2}=.19 * * *$ & $R^{2}=.11 * *$ \\
\hline & $\begin{array}{c}F(12,544)=.8 .91 \\
p<.001\end{array}$ & $\begin{array}{c}F(12,544)=10.49 \\
p<.001\end{array}$ & $\begin{array}{c}F(12,544)=5.86 \\
p<.001\end{array}$ \\
\hline
\end{tabular}

Note: Beta weights $(\beta)$ are from final regression equations with all blocks of variables in the model. 